\title{
Social Problem-Solving and Mild Intellectual Disabilities: Relations With Externalizing Behavior and Therapeutic Context
}

\author{
Maroesjka van Nieuwenhuijzen, Bram Orobio de Castro, Lex Wijnroks, and \\ Adri Vermeer \\ Utrecht University (Utrecht, Netherlands) \\ Walter Matthys \\ University Medical Center (Utrecht, Netherlands)
}

\begin{abstract}
Relations among externalizing behavior, therapeutic context (community care vs. residential care), and social problem-solving by children with mild intellectual disabilities or borderline intelligence were examined. Participants were 186 children (12 to 14 years of age) who responded to a video-based social problem-solving task. Of these, 130 received residential care and the majority suffered from severe externalizing behavior problems. The results indicated that externalizing behavior was related to encoding, generation of aggressive responses, and negative evaluation of assertive responses. Therapeutic context was related to encoding, positive evaluation of assertive responses, and negative evaluation of aggressive responses. Results indicate a discrepancy between appropriate problem-solving skills and behavior in daily life. Implications for interventions are discussed.
\end{abstract}

DOI: $10.1352 / 2009.114: 42-51$

Behavior problems of children with mild intellectual disabilities or borderline intelligence have been studied extensively during the last decade. Research shows high rates of emotional and aggressive behavior problems among such children (Borthwick-Duffy, 1994; Cormack, Brown, \& Hastings, 2000; Dekker, Koot, Van der Ende, \& Verhulst, 2002; Einfeld \& Tonge, 1996; Linna et al., 1999). More specifically, compared to children with average intelligence, children with mild intellectual disabilities or borderline intelligence show less prosocial behavior and more aggressive behavior, poorer social skills, fewer social peer interactions, less acceptance by peers, and more rejection by peers (Gresham \& MacMillan, 1997; Kasari \& Bauminger, 1998).

These findings do not apply to all children, however. Large individual differences in behavior problems exist, and therapeutic contexts differ among these children. Some of them have serious behavior problems but are still able to function reasonably well in the community. Others have such serious social and behavior problems that they live in special institutes for residential treatment (Barnhard, 1994; Koot \& Dekker, 2001).

In order to improve treatment for these behavior problems, it is necessary to understand the cognitive processes underlying behavior problems in children with mild intellectual disabilities and borderline intelligence. To this end, it is important to determine (a) what kind of cognitive skills are related to behavior problems and (b) how different therapeutic contexts might contribute to the development of these skills.

Concerning the first issue of relations between cognitive skills and behavior problems, an important perspective is social information-processing theory (Dodge, 1986). According to this model (Crick \& Dodge, 1994), behavior in social situations is preceded by the mental steps of en- 
coding, interpretation, goal clarification, response generation, and response selection. These mental steps are continuously influenced by the individual's database, or memory store, of social knowledge. In a given social situation, children encode information from the situation and interpret it. On the basis of this information, they subsequently set goals, search their memory for possible responses, evaluate these responses, and select a response for enactment. Individual differences in each of the mental steps of the social informationprocessing model give rise to individual differences in the responses to a particular social situation. Considerable evidence exists to support the hypothesis that the behavior problems of children with average intelligence are related to their social problem-solving skills (Crick \& Dodge, 1994; Lochman \& Wells, 2002; Matthys, Cuperus, \& Van Engeland, 1999; Matthys \& Lochman, 2005; Orobio de Castro, Veerman, Koops, Bosch, \& Monshouwer, 2002).

With respect to children with mild intellectual disabilities or borderline intelligence, the relations between social problem-solving and their behavior are not yet clear. Although in a recent study Van Nieuwenhuijzen et al. (2006) found that the social information-processing model in a modified form explains aggressive behavior in residential children with mild intellectual disabilities or borderline intelligence, we do not know which social problem-solving skills are related to externalizing behavior in these children. In the present study we attempted to resolve this issue.

In three previous studies, researchers compared social problem-solving by children with mild intellectual disabilities or borderline intelligence, with and without accompanying behavior problems. Results of these studies, however, were inconsistent. Leffert and Siperstein (1996) reported that children with externalizing behavior problems were characterized by misinterpretations of benign intent and aggressive response generation. Van Nieuwenhuijzen et al. (2005) also found that children with externalizing problems generated aggressive responses, but did not select aggressive responses. In contrast, Healy and Masterpasqua (1992) noted that children with mild intellectual disabilities and externalizing behavior problems generated fewer aggressive responses.

The results of these studies suggest a relation between at least some patterns of social problemsolving and the externalizing behavior problems that some children with mild intellectual disabilities or borderline intelligence display. Nevertheless, the results have been inconsistent, which may be due to sample diversities, different instruments used, or the study of varying social information-processing steps. For example, in a recent meta-analysis concerning interpretation, Orobio De Castro et al. (2002) demonstrated that findings were dependent on participants' age, sociometric status, referral, and various characteristics of the instruments used. Moreover, only one or two steps from the social information-processing model have generally been considered in each study (Leffert \& Siperstein, 2002); therefore, there is a lack of information on the influence of the other steps.

The second issue concerns the relation of different therapeutic contexts to social problem-solving skills. Children with mild intellectual disabilities or borderline intelligence need special care that fits both their cognitive and social adaptive functioning. In the Netherlands these children are admitted to special schools for instructions in academics and social skills. For a considerable number of children with mild intellectual disabilities or borderline intelligence and serious behavior problems, however, training in social skills is not sufficient. Also in the Netherlands, there is a tradition of residential care for children with mild intellectual disabilities or borderline intelligence who exhibit severe behavior problems. Treatment in residential care addresses behavior problems that are the result of the intellectual disability in combination with additional psychiatric problems and is focused on behavior regulation and teaching social problem-solving strategies. Compared to special schools, contingency management is provided in residential care not only during the hours the child is at school but for the whole day. In addition, ongoing supervision and monitoring of the children's behavior is focused on providing a safe and predictable environment. Although the parents sometimes receive consultation about how to address their children's behavior problems and the children themselves may have access to outpatient counseling, the caretaking context of community care does not typically offer the highly structured program of intervention that the residential institutes provide.

Thus, behavior problems are addressed differently in varying therapeutic contexts. It can be expected that social problem-solving skills are affected more by residential care than by community care. Residential care may benefit the children's social problem-solving in a number of 
ways. Two likely influences are the other residents and child care workers. On the one hand, peers may increase deviant social problem-solving via modeling and reinforcement. On the other hand, direct care staff may help decrease children's deviant social problem-solving via feedback on the children's inappropriate problem-solving strategies. In addition, staff members help to increase children's appropriate social problem-solving skills via modeling, teaching, and reinforcement.

Our aim in the present study was to examine the relations among behavior problems, therapeutic context, and social problem-solving by children with mild intellectual disabilities or borderline intelligence. In order to clarify these relations, we examined, in different therapeutic contexts, multiple steps of the social information-processing model (e.g., encoding of information, interpretation, response generation, response evaluation, self-efficacy, and response selection) with children who have mild intellectual disabilities or borderline intelligence.

\section{Method}

\section{Participants}

The study population consisted of two groups of children, 10 to 14 years of age, with mild intellectual disabilities or borderline intelligence. The first group was selected from residential treatment centers in the Netherlands, where there are 21 special treatment centers for children with mild intellectual disabilities or borderline intelligence who, due to their intellectual disabilities and behavior problems, demonstrate adjustment problems in one or more social contexts, including the family, school, work, and peers. Admission criteria for residential care are IQ between 55 and 85, limitations in social and adaptive behavior, and a chronic need for care, which is consistent with the most recent definition of intellectual disability provided by the American Association on Mental Retardation (AAMR-now the American Association on Intellectual And Developmental Disabilities) (Luckasson et al., 2002). Eight of these treatment centers were selected because of their geographical location; almost the whole country was represented by this selection. In each of these eight treatment centers, all clients between the ages of 10 to 14 receiving residential care and special education services and their parents or caretakers were asked to participate; 130 children and their parents or caregivers agreed.
The second group was composed of 56 children participating in a study by Van Nieuwenhuijzen et al. (2005). They received special education services and lived at home with their families. They attended school programs that serve children who have an IQ between 55 and 85. This research was undertaken with the understanding and written consent of each participant as well as approval by the medical ethical committee of the participating university.

Consequently, 186 children (117 boys, 69 girls) with mild intellectual disabilities or borderline intelligence participated. Their mean age was 12.1 years $(S D=1.28)$ and mean IQ was $71.3(S D$ $=10.4$ ). Children in the total sample had severe behavior problems: the Externalizing Behavior mean T-scores on the Teacher Report Form (Achenbach, 1991) fell within the clinical range $(M=$ 63.51, $S D=12.28)$. A summary of descriptive statistics for the two subgroups is presented in Table 1 .

The externalizing mean scores of the residential care group fell within the clinical range ( $\geq 90$ th percentile). The community care group scored significantly lower on externalizing behavior, $F(1,174)=13.22, p<.001$, although almost half of the children in community care scored in the clinical range as well. The two samples also differed in age, with the residential sample being slightly older, $F(1,184)=20.67, p<.001$ (see Table 1).

\section{Measures}

Intelligence. We determined IQ on the basis of results of individual intelligence testing obtained from school records. In instances in which testing had not been performed within the preceding 12 months, we estimated the child's IQ using the following procedure. For the children in residential

Table 1. Participant Characteristics for the Two Therapeutical Contexts

\begin{tabular}{lccccc}
\hline & \multicolumn{2}{c}{$\begin{array}{c}\text { Community care } \\
(n=56)\end{array}$} & & \multicolumn{2}{c}{$\begin{array}{c}\text { Residential care } \\
(n=130)\end{array}$} \\
\cline { 2 - 3 } \cline { 5 - 6 } Characteristic & Mean & $S D$ & & Mean & SD \\
\hline TRFa T-score & 58.75 & 14.26 & & 65.73 & 10.58 \\
Age & 11.52 & 1.18 & & 12.40 & 1.23 \\
IQ & 70.11 & 13.16 & & 72.04 & 8.90 \\
Gender & $36: 20$ & - & & $81: 49$ & - \\
\hline
\end{tabular}

aTeacher Report Form. 
care, we estimated their intelligence by using the Raven's Standard Progressive Matrices (Raven, Court, \& Raven, 1983), which consists of incomplete arrays of abstract geometrical figures. Participants are asked to discover the relations between the elements in the incomplete arrays and choose the right figure on the basis of this information to complete the array. The internal consistency values are around .90 , and the test-retest reliability varies from .90 for the short term to .80 for the long term. This instrument has moderate to high correlations with other situational tests of intelligence (Raven et al., 1983). For the children in community care, we used the Vocabulary and Block Design subtests from the Dutch version of the Wechsler Intelligence Scale for ChildrenRevised-WISC-RN (Van Haassen et al., 1985) to estimate intelligence level. These two subtests were selected because they are known to strongly correlate with the total WISC-RN score, $r=.86$ (Silverstein, 1970).

Bebavior problems. For each child, the teacher completed the Teacher's Report Form of the Child Behavior Checklist-CBCL (see Achenbach, 1991; for the Dutch version, see Verhulst, Van der Ende, and Koot, 1997). The Teacher Report Form consists of 113 questions about behavioral and emotional problems that are scored on a 3-point scale. Using the Dutch norms, we obtained standardized T-scores for the Externalizing Problems Scale that includes items on aggressive and delinquent behavior. The questionnaire was completed by the teachers who had the most contact hours with the child and who had been teaching the child for at least 3 months. The Dutch version of the Teacher Report Form has been shown to have good reliability and validity for the population in general (Verhulst et al., 1997) and for children with mild intellectual disabilities in particular (Dekker et al., 2002).

Social problem-solving. The Social ProblemSolving Test (Cuperus, 1997; Matthys et al., 1999) was designed to measure social problem-solving skills. The original test consists of 12 video vignettes and a structured interview. For the present study, we revised the original version for use with children who have mild intellectual disabilities (Van Nieuwenhuijzen, Bijman, Lamberix, Wijnroks, \& Matthys, 2001). The number of video vignettes was reduced and the questions were simplified. The revised version consists of five vignettes. Child actors role played the problem of being placed at a social disadvantage twice in each vignette. The vignettes included both peer-entry and provocation situations, which are part of a single factor-Being Disadvantaged (Matthys, Maassen, Cuperus, \& Van Engeland, 2001). Each video vignette involves two parts. First, the social problem is presented. For example, the protagonist is trying to build a Lego plane but is not succeeding; another boy offers to help, but the Lego plane simply breaks into pieces as a result. Second, three alternative solutions to the problem were enacted by the protagonist: prosocial/assertive, antisocial/aggressive, and passive/submissive.

Prior to the presentation of each video vignette, the participant was asked to identify him/ herself with the protagonist. The child was then asked a number of questions regarding the vignette, and the answers were recorded by the research assistant. In the Lego building example, the first question was used to assess the encoding of cues: "What happened in this video clip?" The total number of cues on average was determined by summing the numbers of cues across the five vignettes and dividing by five.

The second question was used to assess the child's interpretation of the presented information: "The plane broke. Why did this happen?" The participant had to choose one of three possible answers: (a) benign intent ("It wasn't his fault, he tried to help me"), (b) unkind (but not hostile) intent ("He's clumsy"), or (c) hostile intent ("He did it on purpose"). We obtained a total score for hostile intent by summing the number of vignettes (out of five) receiving an unkind or hostile answer. A minimum total score of 0 (never chosen) and a maximum total score of 5 (always chosen) was, therefore, possible.

The next question was developed to assess response generation ("What are you going to do?"). After mention of a first response, the participant was asked to think of other ways of responding to the situation. The number of responses provided by the child were coded by the research assistant as was the quality of each response: prosocial/assertive, antisocial/aggressive, or passive/submissive. We determined spontaneous response scores by counting the number of times that an aggressive response, for example, was provided by the child as his or her first response with a minimum score of 0 (never given) and a maximum score of 5 (always given). In this study we were only interested in the aggressive and assertive responses, as previous researchers have indicated that these responses are related to externalizing behavior 
(Crick \& Dodge, 1994). We calculated a total generation score by dividing the total number of responses across the five vignettes by five.

At this point, the participating child was presented the three responses as enacted by the protagonist on the video. The presentation of each response was followed by questions intended to assess the participant's response evaluation and self-efficacy. The first question concerned evaluation on the basis of moral values: "Was this a good way for the child to respond?" The participating child could respond either yes or no. The second question concerned the participant's confidence that he or she would be able to behave in such a manner or selfefficacy: "Would you be able to behave in the same way?" The participating child could respond either yes or no. For each of the three response types, we obtained a total evaluation score and a total selfefficacy score per child by summing the number of positive answers across the five vignettes, with a minimum of 0 (never positive) and a maximum of 5 (alweays positive).

Finally, the three videotaped solutions were again presented one after the other and the participating child was asked: "Which of the three responses would you choose?" In such a manner, we assessed response selection. More specifically, we summed the number of assertive responses and the number of aggressive responses across the five vignettes to determine assertive and aggressive response selection for each child.

To assess interrater reliability for coding of participants' answers to the open questions, both a graduate student and the first author scored these answers for 50 vignettes. The Kappa values were .79 for encoding and .88 for response generation. In previous research, children's answers to the response generation question correlated moderately with actual behavior in real-life problem situations, $r=.30$, and highly with behavior in class as reported by the teacher, $r=.49$ (van Nieuwenhuijzen et al., 2005).

\section{Data Analyses}

In order to determine the relations between externalizing behavior, therapeutic context (residential care vs. community care), and social problem-solving skills by children with mild intellectual disabilities or borderline intelligence, we conducted a series of hierarchical linear multiple regression analyses (HLMR). First, to examine whether externalizing behavior problems contribute uniquely to the variance in any of the social information-processing variables, in each of the analyses we included a single social informationprocessing variable as the dependent variable; age, gender, and IQ were then entered in the first step as control variables; therapeutic context was entered in the second step; externalizing behavior problems was entered in the third step. In order to investigate whether therapeutic context contributes uniquely to the variance in any of the social information-processing variables, we conducted the regression analyses again, but with externalizing behavior problems entered before therapeutic context.

\section{Results}

The results of the HLMR show that after we controlled for age, gender, IQ, and therapeutic context, externalizing behavior explained a significant amount of the variance in encoding situational cues, generation of spontaneous aggressive responses, and positive evaluation of assertive responses. Externalizing behavior was (a) negatively related to situational cues and positive evaluations of assertive responses and (b) positively related to spontaneous aggressive responses (see Table 2 for results of entering both externalizing behavior and therapeutic context last in the model).

After controlling for the effects of age, gender, IQ, and externalizing behavior, we found that therapeutic context explained a significant amount of variance of the encoding variables (i.e., total and situational cues). Residential care was negatively related to cues in general and situational cues in particular (see Table 2). Further, therapeutic context contributed significantly to the evaluation and selection of aggressive and assertive responses variables and to children's self-efficacy for enacting these responses. Residential care was positively related to positive evaluations and selection of assertive responses and to confidence about the ability to enact an assertive response. In turn, residential care was negatively related to positive evaluations and selection of aggressive responses (see Table 2).

\section{Discussion}

In the present study we examined the relations among externalizing behavior, therapeutic context, and social problem-solving by children with mild intellectual disabilities or borderline intelligence. With regards to the relation between externalizing behavior and social problem-solving, 
Table 2. Unique Contributions of Externalizing Behavior and Therapeutic Context to Variance in Separate Social-Information Processing Variables

\begin{tabular}{|c|c|c|c|c|}
\hline Dependent variable/Predictors & Beta & $R^{2}$ change & $F$ change & $R^{2}$ total model \\
\hline \multicolumn{5}{|l|}{ Total cues } \\
\hline Age & .13 & .02 & .88 & \\
\hline Gender & -.11 & & & \\
\hline IQ & -.01 & & & \\
\hline Externalizing behavior & -.08 & .01 & .98 & \\
\hline Therapeutic context & $-.33 * * *$ & .09 & $14.81 * * *$ & .13 \\
\hline \multicolumn{5}{|l|}{ Situational cues } \\
\hline Age & .10 & .03 & 1.42 & \\
\hline Gender & -.06 & & & \\
\hline IQ & -.01 & & & \\
\hline Externalizing behavior & $-.16^{*}$ & .02 & $4.42 *$ & \\
\hline Therapeutic context & $-.48 * * *$ & .17 & $35.98 * * *$ & .27 \\
\hline \multicolumn{5}{|l|}{ Spontaneous assertive response } \\
\hline Age & .23 & .05 & 2.39 & \\
\hline Gender & -.03 & & & \\
\hline IQ & .07 & & & \\
\hline Externalizing behavior & -.09 & .01 & .82 & \\
\hline Therapeutic context & -.08 & .01 & .93 & .06 \\
\hline \multicolumn{5}{|l|}{ Evaluation assertive response } \\
\hline Age & .02 & .01 & .28 & \\
\hline Gender & .02 & & & \\
\hline $\mathrm{IQ}$ & -.02 & & & \\
\hline Externalizing behavior & $.34 * * *$ & .10 & $17.59 * * *$ & \\
\hline Therapeutic context & .04 & .00 & .19 & .12 \\
\hline \multicolumn{5}{|l|}{ Evaluation aggressive response } \\
\hline Age & -.11 & .04 & 1.92 & \\
\hline Gender & .05 & & & \\
\hline $\mathrm{IQ}$ & .01 & & & \\
\hline Externalizing behavior & $-.16^{*}$ & .02 & $4.61 *$ & \\
\hline Therapeutic context & $.56 * * *$ & .24 & $51.09 * * *$ & .28 \\
\hline \multicolumn{5}{|l|}{ Evaluation aggressive response } \\
\hline Age & -.12 & .06 & $3.34 *$ & \\
\hline Gender & .04 & & & \\
\hline IQ & -.05 & & & \\
\hline Externalizing behavior & .04 & .00 & .25 & \\
\hline Therapeutic context & $-.29 * * *$ & .07 & $11.27 * *$ & .13 \\
\hline \multicolumn{5}{|l|}{ Self-efficacy assertive response } \\
\hline Age & .07 & .08 & $4.70 * *$ & \\
\hline Gender & .15 & & & \\
\hline IQ & -.00 & & & \\
\hline Externalizing behavior & -.14 & .02 & 3.32 & \\
\hline Therapeutic context & $.36 * * *$ & .10 & $18.33 * * *$ & .19 \\
\hline \multicolumn{5}{|l|}{ Self-efficacy aggressive responses } \\
\hline Age & -.04 & .02 & .97 & \\
\hline
\end{tabular}


Table 2. Continued

\begin{tabular}{lcccc}
\hline Dependent variable/Predictors & Beta & $R^{2}$ change & $F$ change & $R^{2}$ total model \\
\hline Gender & .11 & & & \\
IQ & -.02 & & & \\
Externalizing behavior & .02 & .00 & .04 & .03 \\
$\quad$ Therapeutic context & -.11 & .01 & 1.39 & \\
Aggressive response selection & & & & \\
Age & .04 & .02 & 1.18 & .07 \\
Gender & -.06 & & & \\
IQ & -.07 & & .11 & \\
Externalizing behavior & .03 & .00 & $8.07 * *$ & \\
Therapeutic context & $-.25^{* *}$ & .05 & & \\
Assertive response selection & & & & \\
Age & $.23^{* *}$ & .07 & $.98 *$ & .07 \\
Gender & .05 & & & \\
IQ & .13 & .00 & .60 & \\
Externalizing behavior & .02 & .02 & 3.60 & \\
Therapeutic context & .17 &
\end{tabular}

Note. The table displays the results when externalizing behavior and therapeutic context were each entered last in the model.

$* p<.05 . * p<.01 . * \% p<.001$.

results showed that externalizing behavior was related to encoding of situational cues, generation of aggressive responses, and evaluation of assertive responses. Externalizing behavior problems were negatively related to encoding of situational cues (i.e., to greater difficulties in describing what happened in the video vignettes). Second, these problems were positively related to spontaneous aggressive response generations. Furthermore, externalizing behavior problems were negatively related to positive evaluations of assertive responses. These results are consistent with the results of earlier studies with children who had mild intellectual disabilities (Leffert \& Siperstein, 1996; van Nieuwenhuijzen et al., 2005) as well as children with average intelligence (Crick \& Dodge, 1994).

When analyzing the relation between therapeutic context and social problem-solving, we found that therapeutic context was related to encoding cues, evaluation, self-efficacy, and selection of assertive and aggressive responses. Residential care was negatively related to encoding of cues in general and situational cues in particular. In other words, children in residential care appear to have difficulties with the encoding of social information. A similar result has also been reported by Matthys et al. (1999) for children with average intelligence and externalizing behavior problems. Furthermore, residential care was neg- atively related to positive evaluations of aggressive responses and positively related to positive evaluations of assertive responses.

Results, however, have to be interpreted with care because our sample was selective; only children whose parents agreed to participate were included in the study. Therefore, a selection bias may have affected the results. However, we selected schools and residential centers that were geographically representative, and the ratio of boys to girls was representative of the overall population of children with mild intellectual disabilities or borderline intelligence.

Children with externalizing behavior problems in residential care tended to generate aggressive responses, but at the same time did not evaluate those responses positively and did not feel confident in enacting them. On the contrary, they evaluated assertive responses positively and felt confident in enacting these responses. In addition, they were not likely to select aggressive responses as the best response. These results are consistent with recent findings (van Nieuwenhuijzen et al., 2005) and the results of a study by Jacobs, Turner, Faust, and Stewart (2002), who found that children with mild intellectual disabilities generated more inadequate responses than did children with average intelligence but were equally good or even better at the selection of adequate responses. 
These apparently contrasting findings suggest that children with mild intellectual disabilities or borderline intelligence with externalizing behavior problems in residential care are able to recognize and select adequate solutions for social problems, but they do not draw upon these for spontaneous response generation and in real-life situations (cf. van Nieuwenhuijzen et al., 2005).

The discrepancy between appropriate problem-solving responses by children in residential care and their externalizing behavior in daily life may be the result of (a) a discrepancy between reflective problem-solving in response to hypothetical vignettes and automatic social problemsolving in daily life in general; and (b) experiences in residential care, which may have increased the use of social problem-solving skills when reflection is prompted, without sufficient transfer to actual social situations in children's daily lives.

Concerning the first issue, in two recently published studies, van Nieuwenhuijzen et al. (2005) demonstrated that aggressive responses to vignettes are moderately related with actual aggressive behavior in comparable experimental play situations and that effect sizes for the relation between social information-processing and behavior are generally larger in real life than in hypothetical vignette situations (Orobio de Castro et al., 2002). There are several possible reasons why transfer to real life is difficult for these children. One explanation is that children may have ingrained patterns that have developed from early childhood on and are hard to change in a relatively short period of time. Second, in real-life situations people are more emotionally aroused than in hypothetical situations, which affects their social problem-solving (Lemerise \& Arsenio, 2000). A third explanation is that peer group norms influence social problem-solving in residential settings. Even though a child knows how to behave properly in a social problem situation, he or she may prefer responding aggressively in order to adjust to the peer group norms.

Concerning the second issue of the effect of residential care on the discrepancy between reflective social problem-solving and spontaneous and real-life responses, we can only speculate about the way direct-care staff influence children's social problem-solving. Because direct-care staff disapprove of aggressive responses, children may not feel confident in enacting such responses. In addition, this may result in not selecting an aggressive response. Furthermore, assertive responses are constantly modeled and reinforced by care workers, which may lead to the children's confidence in enactment. However, the higher level of reflective responding does not explain the differences between children in residential and community care. Children in residential care are apparently capable of reflecting about how to solve social problems at a somewhat more mature level than are children in community care. This does not mean that they are capable of reasoning adequately about social problems because children in residential care still tend to generate aggressive responses.

The present study was not designed to provide a definitive answer to the question of causality. Further research is needed to study social problem-solving skills as mediating factors in a randomized clinical trial to answer the question about how residential care affects social problemsolving.

Perhaps the effect of appropriate social problem-solving strategies on behavior could be improved by including cognitive behavioral interventions adapted to the developmental level of these children. Indeed, cognitive behavioral intervention programs focused on social problem-solving skills have proven effective with children who have externalizing problems and average intelligence (e.g., Lochman \& Wells, 2002; O’Reilly, Lancioni, Sigafoos, O’Donoghue, et al., 2004; O’Reilly, Lancioni, Sigafoos, Green, et al., 2004; Zonnevylle-Bender, Matthys, Van de Wiel, \& Lochman, 2007). However, training of the reflective response decision processes may only be effective when the generation of various response alternatives has been explicitly emphasized and trained and if evaluation and selection of response alternatives can be linked to response generation. Children may be taught to think in terms of consequences of various alternatives by giving them feedback on the responses that they themselves generate. Moreover, given the difficulties that apparently are involved in transferring social problem-solving skills to daily life, training of social problem-solving skills in children with mild intellectual disabilities should be undertaken not only in special settings but also in daily life situations in order to facilitate the transfer of newly acquired skills. Not only should children in residential care be trained in social problem-solving skills but direct-care staff and teachers should be included in the training as well, for they can reinforce the children in the use of appropriate problem-solving 
skills in everyday social interactions. For community settings such training should be offered to the parents as well. In light of the present findings and their implications for both current theory and practice, further research along these lines is certainly needed.

\section{References}

Achenbach, T. (1991). Manual for the Teacher's Report Form and 1991 Profile. Burlington: University of Vermont, Department of Psychiatry.

Barnhard, M. (1994). Instellingen voor licht verstandelijk gehandicapte kinderen en jongeren [Institutions for children and adolescents with mild intellectual disabilities]. Utrecht, The Netherlands: Nzi.

Borthwick-Duffy, S. A. (1994). Epidemiology and prevalence of psychopathology in people with mental retardation. Journal of Clinical Psychology, 62, 17-27.

Cormack, K. F. M., Brown, A. C., \& Hastings, R. P. (2000). Behavioural and emotional difficulties in students attending schools for children and adolescents with severe intellectual disabilities. Journal of Intellectual Disability Research, 44, 124-129.

Crick, N. R., \& Dodge, K. A. (1994). A review and reformulation of social information processing mechanisms in children's social adjustment. Psychological Bulletin, 115, 74-101.

Cuperus, J. M. (1997). Sociale probleemoplossing bij kinderen met gedragsstoornissen [Social problemsolving in children with behaviour problems]. Unpublished dissertation, Utrecht University, Utrecht, The Netherlands.

Dekker, M. C., Koot, H. M., Van der Ende, J., \& Verhulst, F. C. (2002). Emotional and behavioral problems in children and adolescents with and without intellectual disability. Journal of Child Psychology and Psychiatry, 43, 1087-1098.

Dodge, K. A. (1986). A social information processing model of social competence in children. In M. Perlmutter (Ed.), Minnesota symposium on child psychology: Vol. 18. Cognitive perspectives on children's social and behavioral development (pp. 77-125). Hillsdale, NJ: Erlbaum.

Einfeld, S. L., \& Tonge, B. J. (1996). Population prevalence of psychopathology in children and adolescents with intellectual disability: II.
Epidemiological findings. Journal of Intellectual Disability Research, 40, 99-109.

Gresham, F. M., \& MacMillan, D. L. (1997). Social competence and affective characteristics of students with mild disabilities. Reviere of Educational Research, 67, 377-415.

Healy, K. N., \& Masterpasqua, F. (1992). Interpersonal cognitive problem-solving among children with mental retardation. American Journal on Mental Retardation, 96, 367-372.

Jacobs, L., Turner, L. A., Faust, M., \& Stewart, M. (2002). Social problem-solving of children with and without mental retardation. Journal of Developmental and Physical Disabilities, 14, 37-50.

Kasari, C., \& Bauminger, N. (1998). Social and emotional development in children with mental retardation. In J. A. Burack, R. M. Hodapp, \& E. Zigler (Eds.), Handbook of mental retardation and development (pp. 411-433). Cambridge: Cambridge University Press.

Koot, H. M., \& Dekker, M. C. (2001). Handleiding voor de VOG. Ouder-en leerkrachtversie. (Manual for the Vragenlijst over Ontwikkeling en Gedrag [VOG; Developmental Behavior Checklist, $D B C]$ ). Rotterdam, The Netherlands: Erasmus Medical Center-Sophia Children's Hospital/Erasmus University Rotterdam

Leffert, J. S., \& Siperstein, G. N. (1996). Assessment of social-cognitive processes in children with mental retardation. American Journal on Mental Retardation, 100, 441-455.

Leffert, J. S., \& Siperstein, G. N. (2002). Social cognition: A key to understanding adaptive behavior in individuals with mild mental retardation. International Review of Research in Mental Retardation, 25, 135-181.

Lemerise, E. A., \& Arsenio, W. F. (2000). An integrated model of emotion processes and cognition in social information processing. Child Development, 71, 107-118.

Linna, S. L., Moilanen, I., Ebeling, H., Piha, J., Kumpulainen, K., Tamminen, T., \& Almqvist, F. (1999). Psychiatric symptoms in children with intellectual disability. European Child \& Adolescent Psychiatry, 8(Suppl. 4), 77-82.

Lochman, J. E., \& Wells, K. C. (2002). Contextual social-cognitive mediators and child outcome: A test of the theoretical model in the Coping Power program. Development and Psychopathology, 14, 945-967.

Luckasson, R., Borthwick-Duffy, S., Buntinx, W., Coulter, D., Craig, E., Reeve, A., Schalock, 
R., Snell, M., Spitalnik, D., Spreat, S., \& Tassé, M. (2002). Mental retardation: Definition, classification, and systems of supports (10th ed.). Washington, DC: American Association on Mental Retardation.

Matthys, W., Cuperus, J. M., \& Van Engeland, H. (1999). Deficient social problem-solving in boys with ODD/CD, with ADHD, and with both disorders. Journal of the American Academy of Child and Adolescent Psychiatry, 38, 311321.

Matthys, W., \& Lochman, J. E. (2005). Social problem-solving in aggressive children. In M. McCurran \& J. McGuire (Eds.), Social problemsolving and offending: Evidence, evaluation, and evolution (pp. 51-66). Chichester: Wiley.

Matthys, W., Maassen, G. H., Cuperus, J. M., \& Van Engeland, H. (2001). The assessment of the situational specificity of children's problem behavior in peer-peer context. Journal of Child Psychology and Psychiatry, 42, 413-420.

O’Reilly, M. F., Lancioni, G. E., Sigafoos, J., Green, V. A., Ma, C. H., \& O’Donoghue, D. O. (2004). A further comparison of external control and problem-solving interventions to teach social skills to adults with intellectual disabilities. Behavioral Interventions, 19, 173186.

O’Reilly, M. F., Lancioni, G. E., Sigafoos, J., O’Donoghue, D. O., Lacey, C., \& Edrisinha, C. (2004). Teaching social skills to adults with intellectual disabilities: A comparison of external control and problem-solving interventions. Research in Developmental Disabilities, 25, 399-412.

Orobio de Castro, B., Veerman, J. W., Koops, W., Bosch, J. D., \& Monshouwer, H. J. (2002). Hostile attribution of intent and aggressive behavior: A meta-analysis. Child Development, 73, 916-934.

Raven, J. C., Court, J. H., \& Raven, J. (1983). Manual for Raven's Progressive Matrices and Vocabulary Scales. London: Lewis.

Silverstein, A. B. (1970). Reappraisal of the validity of WAIS, WISC, and WPPSI short forms. Journal of Consulting and Clinical Psychology, 34, 12-14.

Van Haassen, P. P., De Bruyn, E. E. J., Pijl, Y. J., Poortinga, Y. H., Lutje Spelberg, H. C., Van der Steene, G., Coetsier, P., Spoelders-Claes, R., \& Stinissen, J. (1985). WISC-R, Nederlandstalige uitgave [WISC-R, Dutch version]. Lisse: Swets \& Zeitlinger.
Van Nieuwenhuijzen, M., Bijman, E. R., Lamberix, I. C. W., Wijnroks, L., \& Matthys, W. (2001). Handleiding voor de SPT-MLK 2. [Manual for the SPT-MID]. Utrecht, The Netherlands: Utrecht University, Department of Special Education.

Van Nieuwenhuijzen, M., Bijman, E. R., Lamberix, I. C. W., Wijnroks, L., Orobio de Castro, B., Vermeer, A., \& Matthys, W. (2005). Do children do what they say? Responses to hypothetical and real-life social problems in children with mild intellectual disabilities and behaviour problems. Journal of Intellectual Disability Research, 49, 419-433.

Van Nieuwenhuijzen, M., Orobio de Castro, B., Van der Valk, I., Wijnroks, L., Vermeer, A., \& Matthys, W. (2006). Do social information processing models explain aggressive behaviour by children with mild intellectual disabilities in residential care? Journal of Intellectual Disability Research, 50, 801-812.

Verhulst, F. C., Van der Ende, J., \& Koot, M. H. (1997). Handleiding voor de Teacher's Report Form $(T R F)[$ Manual for the TRF]. Rotterdam, The Netherlands: Department of Child and Adolescent Psychiatry, Sophia Children's Hospital/Academic Hospital Rotterdam-Erasmus University Rotterdam.

Zonnevylle-Bender, M. J. S., Matthys, W., Van de Wiel, N. M. H., \& Lochman, J. E. (2007). Preventive effects of treatment of disruptive behavior disorder in middle childhood on substance use and delinquent behavior. Journal of the American Academy of Child and Adolescent Psychiatry, 46, 33-39.

Received 6/11/07, accepted 5/30/08.

Editor-in-charge: Leonard Abbeduto

This research was supported by OCB, Saltho (Hondsberg La Salle and Stichting St Anna/Gastenhof), and Stichting De Bruggen. The authors thank the children, their teachers, and the staff of the following institutes for their participation: De Bruggen, De Eik, 's Heerenloo Kwadrant (locaties Groot Emaus, Meilust, and Van Arkel), OCB, OPL, and Saltho (locaties Gastenhof, La Salle). The authors also gratefully acknowledge the contributions of all of their graduate students to the collection of the data. Correspondence regarding this article should be sent to Maroesjka van Nieuwenhuijzen, Developmental Psychology, Utrecht University, Utrecht 3508 TC, Netherlands. E-mail: m.vannieuwenhuijzen@uu.nl 